\title{
A disaster risk management performance index
}

\author{
Martha Liliana Carreño · Omar Darío Cardona • \\ Alex H. Barbat
}

Received: 17 October 2005/ Accepted: 11 May 2006/Published online: 7 February 2007

(C) Springer Science+Business Media B.V. 2007

\begin{abstract}
The Risk Management Index, RMI, proposed in this paper, brings together a group of indicators that measure risk management performance and effectiveness. These indicators reflect the organizational, development, capacity and institutional actions taken to reduce vulnerability and losses in a given area, to prepare for crisis and to recover efficiently from disasters. This index is designed to assess risk management performance. It provides a quantitative measure of management based on predefined qualitative targets or benchmarks that risk management efforts should aim to achieve. The design of the RMI involved establishing a scale of achievement levels or determining the distance between current conditions and an objective threshold or conditions in a reference country, sub-national region, or city. The proposed RMI is constructed by quantifying four public policies, each of which is described by six indicators. The mentioned policies include the identification of risk, risk reduction, disaster management, and governance and financial protection. Risk identification comprises the individual perception, social representation and objective assessment; risk reduction involves the prevention and mitigation; disaster management comprises response and recovery; and, governance and financial protection policy is related to institutionalization and risk transfer. Results at the urban, national and sub-national levels, which illustrate the application of the RMI in those scales, are finally given.
\end{abstract}

Keywords Risk management $\cdot$ Performance of risk management index · Decision-making

M. L. Carreño $(\bowtie) \cdot$ A. H. Barbat

Universidad Politécnica de Cataluña, Campus Norte. C/Gran Capitán sn, Mod. C1, 08034 Barcelona, Spain

e-mail: liliana@cimne.upc.edu

O. D. Cardona

Universidad Nacional de Colombia, Campus Palogrande, IDEA, Cra. 27, No. 64-60,

Manizales, Colombia 


\section{Methodological approach using indicators}

Several methods based on indicators and other figures have been proposed to evaluate vulnerability and disaster risk issues. The contributions of Bates and Peacock (1992), Cutter (1994), Tucker et al. (1994), Davidson (1997), Puente (1999), Cardona et al. (2003a, b), UNDP (2004), World Bank (2004) and Carreño et al. (2005, 2006), among others, attempted to measure vulnerability and risk-related aspects using quantitative or qualitative indicators. In these studies, vulnerability or disaster risk is evaluated from different point of views, using techniques that are, certainly, similar in method but different in purpose and scope with that used in the present article. The mentioned studies have as an objective the evaluation of vulnerability and risk by means of indicators and not the assessment of the effectiveness or performance of risk management, which is the objective of the present paper.

No specific indicators exist in the countries, widely accepted, to valuate directly the performance of risk management or other relevant issues that reflect what we want to measure as risk management. Some initiatives have been taken at regional and national levels (Mitchell 2003). However, in all cases, this type of initiative has been considered subjective and arbitrary, due to their normative character. One of the principle efforts at defining those aspects that define risk management has been made within the action framework led by the ISDR (2003) where, in draft form, various thematic areas, components and possible performance evaluation criteria are proposed (Cardona et al. 2003a, b). In any case, it is necessary to evaluate the variables in a quantit (Benson 2003; Brigug Davis 2003; Masure 2003). The effort to measure risk managemen
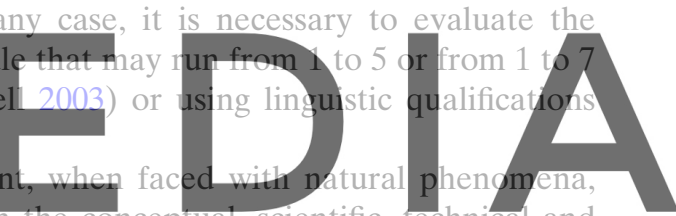

using indicators is a major challenge from the conceptual, scientific, technical and numerical perspectives. Indicators must be transparent, robust, representative and Register for free at https, Www.scipedia.com to download the version without the watermark

It is important to dispose of evaluation methodologies facilitating management risk aggregation and comparison between countries, cities or regions, or any other territorial level. Also, the methodology should be easy to be applied in different time periods, in order to analyze the risk management evolution. In risk management assessment, it is necessary involving data with incommensurable units or information that only can be valuated using linguistic estimates. This is the reason why we are using multi-attribute (or multi-criteria) composite indicators and the fuzzy sets theory as tools to evaluate the effectiveness of risk management. Fuzzy sets have not perfectly defined limits, that is to say the transition between membership and nonmembership of a variable to the set is gradual. This property is useful when flexibility is needed in modeling, using linguistic or qualitative expressions, as much, few, light, severe, scarce, incipient, moderate, reliable, etc.

\section{The Risk Management Index, RMI}

\subsection{Description of the RMI}

The RMI was designed to assess risk management performance and, by this way, its effectiveness. It provides a quantitative measure of management based on 
predefined qualitative targets or benchmarks that risk management efforts should aim to achieve. The design of the RMI involved establishing a scale of achievement levels (Davis 2003; Masure 2003) or determining the distance between current conditions and an objective threshold or conditions in a reference country (Munda 2003). The RMI was constructed by quantifying four public policies, each of which had six indicators. Risk identification index, $\mathrm{RMI}_{\mathrm{RI}}$, is a measure of individual perceptions, of how those perceptions are understood by society as a whole, and the objective assessment of risk. Risk reduction index, $\mathrm{RMI}_{\mathrm{RR}}$, involves prevention and mitigation measures. Disaster management index, $\mathrm{RMI}_{\mathrm{DM}}$, involves measures of response and recovery, and governance and financial protection, $\mathrm{RMI}_{\mathrm{FP}}$, measures the degree of institutionalization and risk transfer. The four public policies and their indicators were defined after an agreement with several stakeholders and evaluators. Any country or city could redefine them according to own specificities, whereas the parameters are maintained the same in the distinct evaluations over time, in order to make a consistent follow-up of the risk management. The RMI is defined as the average of the four composite indicators

$$
\mathrm{RMI}=\left(\mathrm{RMI}_{\mathrm{RI}}+\mathrm{RMI}_{\mathrm{RR}}+\mathrm{RMI}_{\mathrm{DM}}+\mathrm{RMI}_{\mathrm{FP}}\right) / 4
$$

Six indicators are proposed for each public policy. Together, these serve to characterize the risk management performance of a country, region or city. Using a Jarger number of indicators could be redundant and unnecessary and could make the weighting of each indicator difficult. Following the performande management method dicator is based on optimal) that correspon formance levels (low, to a range odological approach permits the use of each reference level simultaneously as a

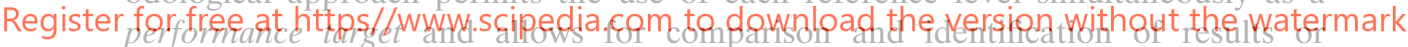

achievements. Government efforts at formulating, implementing, and evaluating policies should bear these performance targets in mind. Alternatively, RMI can be estimated as the weighted sum of crisped numeric values ( 1 to 5 , for example), instead of fuzzy sets of linguistic valuation, as in the proposed method, using a computer application. However, this simplification eliminates risk management nonlinearity, having less appropriated outcomes.

The subindices of risk management conditions for each type of public policy are obtained as

$$
\mathrm{RMI}_{c(\mathrm{RI}, \mathrm{RR}, \mathrm{DM}, \mathrm{FP})}^{t}=\left.\frac{\sum_{i=1}^{N} w_{i} I_{i c}^{t}}{\sum_{i=1}^{N} w_{i}}\right|_{(\mathrm{RI}, \mathrm{RR}, \mathrm{DM}, \mathrm{FP})}
$$

where $w_{i}$ is the weight assigned to each indicator, corresponding to each indicator for the territorial unity $c$ taken into consideration and in the time period $t$, normalized or obtained by the defuzzification of the linguistic values. These represent the risk management performance levels defined by each public policy, respectively. Such linguistic values, according to the proposal of Cardona (2001) and Carreño (2001), 
are the same as a fuzzy set that have a membership function of the bell or sigmoidal (at the extremes) type, given parametrically by the equations

$$
\begin{gathered}
\operatorname{bell}(x ; a, b, c)=\frac{1}{1+\left|\frac{x-c}{a}\right|^{2 b}} \\
\operatorname{sigmoidal}(x ; a, c)=\frac{1}{1+\exp [-a(x-c)]}
\end{gathered}
$$

where the parameter $b$ is usually positive and $a$ controls the slope at the crossing point, at 0.5 of membership, and $x=c$. Figure 1a shows these membership functions.

The shape of these membership functions follow a non-linear behavior described by a sigmoid, as proposed by Carreño et al. (2004), in order to characterize the performance of risk management and the level or feasibility of effectiveness.

The response of a socio technical system to risk is equivalent to a level of adaptation according to the level of effectiveness of its technical structure and its organization. These produce various patterns of action, inaction, innovation and determination when faced with risk. According to Comfort (1999), various types of response may occur depending on the technical structure, the flexibility and the cultural openness to the use of technology. These types of response are: nonadaptive response (inadequate for the existing level of risk and the performance is low or non-existent); emergent adaptation (insufficient but incipient); adaptive adaptive (innovating, creative, and spontaneous; that is, outstanding and optimaly.
Membership functions for fuzzy sets are defined, representing the qualification
levels for the indicators and are used in processing the information. The value of the

Register for free at https//www.scipedir.com to Mowanloald thels version without the watermark
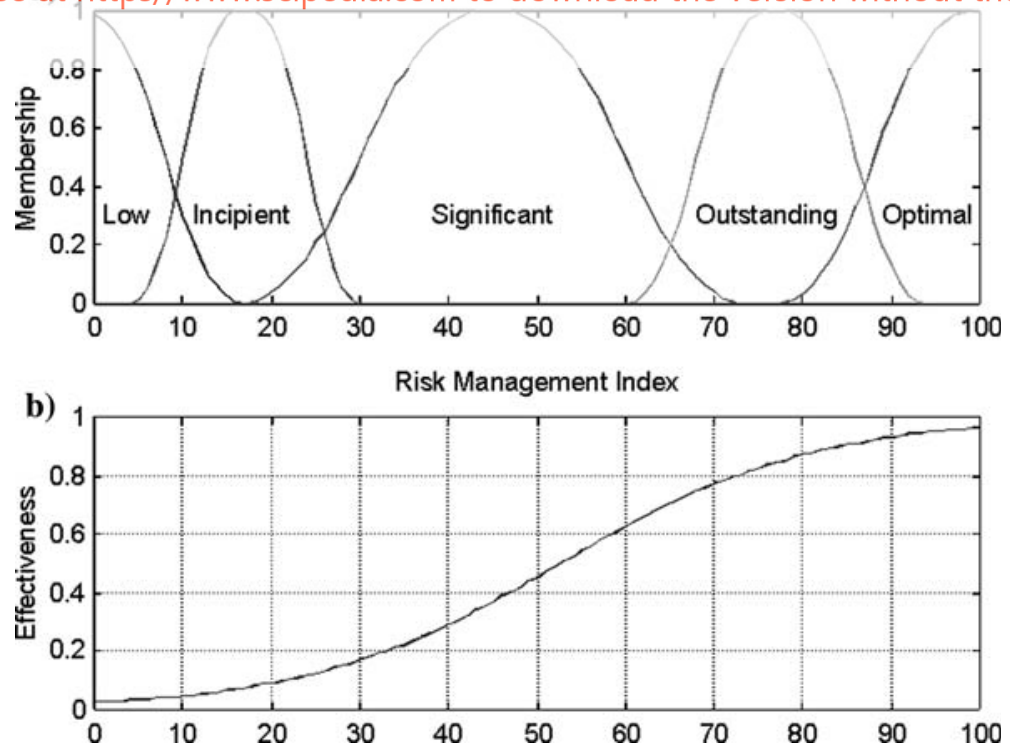

Fig. 1 (a) Functions that represents the qualification level; and (b) Effectiveness degree of the risk management 
indicators is given in the $x$-axis of Fig. 1a and the membership degree for each level of qualification is given in the $y$-axis, where 1 is the total membership and 0 the nonmembership. Risk management performance is defined by means of the membership of these functions, whose shape corresponds to the sigmoid function shows in Fig. 1b, in which the effectiveness of the risk management is represented as a function of the performance level. Figure $1 \mathrm{~b}$ shows that increasing risk management effectiveness is non-linear, due to the fact that it is a complex process. Progress is slow in the beginning, but once risk management improves and becomes sustainable, performance and effectiveness also improve. Once performance reaches a high level, additional (smaller) efforts increase effectiveness significantly but, at the lower levels, improvements in risk management are negligible and unsustainable and, as a result, they have little or no effectiveness.

It is necessary that experts who know the actual risk management progress in the studied area give qualifications of the indicators and assign relative importance between them for each public policy according to their experience and knowledge. These qualifications are processed using the Analytic Hierarchy Process (AIIP) to assign weights, process which is explained in Appendix. Once these have been weighted and aggregated, they form a fuzzy set from which it is hoped to obtain a reply or result. In order to achieve this transformation we need to undergo a process of defuzzification of the obtained membership function and extract from this its concentrated or crisp value. This is the same as extracting an index.

Weights assigned sum
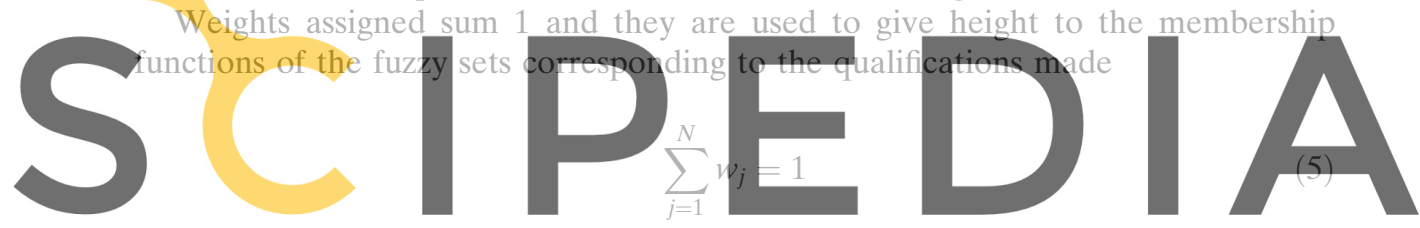

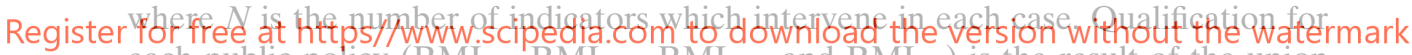
each public policy $\left(R M I_{R I}, R M I_{R R}, R M I_{D M}\right.$ and $\left.R M I_{F P}\right)$ is the result of the union of the weighted fuzzy sets

$$
\mu_{\mathrm{RMI}_{\mathrm{P}}}=\max \left(w_{1} \times \mu_{C}\left(C_{1}\right), \ldots, w_{N} \times \mu_{C}\left(C_{N}\right)\right)
$$

where $w_{1}$ to $w_{N}$ are the weights of the indicators of Fig. $2, \mu_{C}\left(C_{1}\right)$ to $\mu_{C}\left(C_{N}\right)$ are the membership functions of the estimates made for each indicator and $\mu_{\mathrm{RMI} i}$ is the membership function of the RMI qualification of each public policy $p$. The RMI value is obtained from the defuzzification of this membership function, using the method of centroid of area, COA

$$
\mathrm{RMI}_{\mathrm{P}}=\left[\max \left(w_{1} \times \mu_{C}\left(C_{1}\right), \ldots, w_{N} \times \mu_{C}\left(C_{N}\right)\right)\right]_{\mathrm{centroid}}
$$

This technique consists in estimating the area and the centroid of each set and obtaining a concentrated value by dividing the sum of the product amongst them by the sum of the areas

$$
\bar{X}=\frac{\sum A_{i} \bar{x}_{i}}{\sum A_{i}}
$$




$$
\mathrm{COA}=\frac{\int_{X} \mu_{A}(x) x \mathrm{~d} x}{\int_{X} \mu_{A}(x) \mathrm{d} x}
$$

Finally, the average of the four indexes provides the total RMI

\subsection{Indicators for risk identification}

It is important to recognize and understand the collective risk to design prevention and mitigation measures. It depends on the individual and social risk awareness and the methodological approaches to assess it. It then becomes necessary to measure risk and portray it by means of models, maps, and indices capable of providing accurate information for society as a whole and, in particular, for decision-makers. Methodologically, risk identification includes the evaluation of hazards, the characteristics of vulnerability in the face of these hazards, and estimates of the potential impacts during a particular period of exposure. The measurement of risk seen as a basis for intervention is relevant (Carreño et al., 2005, 2006) when the population recognizes and understands that risk. Figure 2 shows the $\mathrm{RMI}_{\mathrm{RI}}$ composition for risk identification.
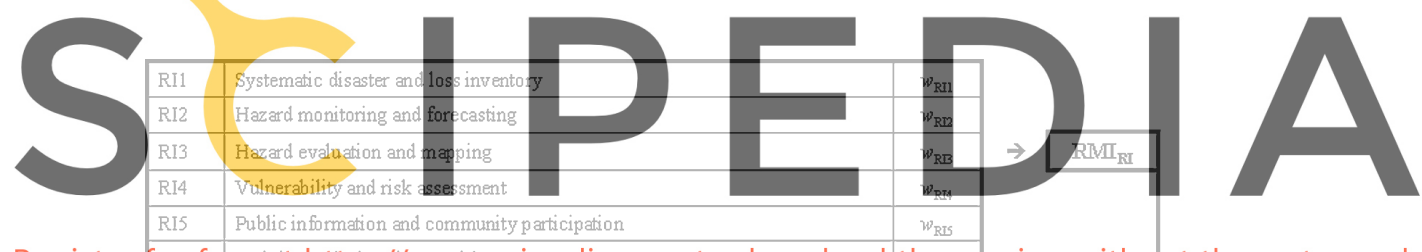

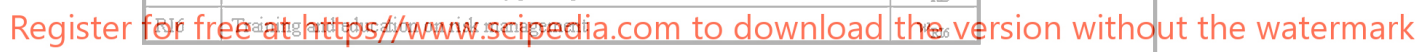

\begin{tabular}{|l|l|l|}
\hline$R R 1$ & Risk consideration in land use and urban planning & $w_{R R 1}$ \\
\hline$R R 2$ & Hydrographical basin intervention and environmental protection & $w_{R R 2}$ \\
\hline$R R 3$ & Implementation of hazard-event control and protection techniques & $w_{R R 3}$ \\
\hline$R R 4$ & Housing improvement and human settlement relocation from prone-areas & $w_{R R}$ \\
\hline$R R 5$ & Updating and enforcement of safety standards and construction codes & $w_{R R}$ \\
\hline RR6 & Reinforcement and retro fitting of public and private assets & $w_{R R 6}$ \\
\hline
\end{tabular}

\begin{tabular}{|l|l|l|}
\hline DM1 & Organization and coordination of emergency op erations & $w_{\mathrm{DM} 1}$ \\
\hline DM2 & Emergency response planning and implementation of warning systems & $w_{\mathrm{DMC}}$ \\
\hline DM3 & Endowment of equipments, tools and infrastructure & $w_{\mathrm{DNB}}$ \\
\hline DM4 & Simulation, updating and test of inter institutional response & $w_{\mathrm{DN}}$ \\
\hline DM5 & Community preparedness and training & $w_{\mathrm{DNS}}$ \\
\hline DM6 & Rehabilitation and reconstruction planning & $w_{\mathrm{DM} 6}$ \\
\hline
\end{tabular}

$\rightarrow \mathrm{RMI}_{\mathrm{DM}}$

\begin{tabular}{|l|l|l|}
\hline FP1 & Interinstitutional, multisectoral and decentralizing organization & $w_{\mathrm{PP} 1}$ \\
\hline FP2 & Reserve funds for institutional strengthening & $w_{\mathrm{PP} 2}$ \\
\hline FP3 & Budget allocation and mobilization & $w_{\mathrm{PP} 3}$ \\
\hline FP4 & Implementation of social safety nets and funds response & $w_{\mathrm{Pp} 4}$ \\
\hline FP5 & Insurance coverage and loss transfer strategies of public assets & $w_{\mathrm{PPS}}$ \\
\hline FP6 & Housing and private sector insurance and reinsurance coverage & $w_{\mathrm{PP} 6}$ \\
\hline
\end{tabular}

$\mathrm{RMI}_{\mathrm{FP}}$

Fig. 2 Component indicators for RMI

Springer 


\subsection{Indicators for risk reduction}

The major aim of risk management is to reduce risk. Reducing risk generally requires the implementation of structural and non-structural prevention and mitigation measures. It implies a process of anticipating potential sources of risk, putting into practice procedures and other measures to either avoid hazard, when it is possible, or reduce the economic, social and environmental impacts through corrective and prospective interventions of existing and future vulnerability conditions. Figure 2 shows the $\mathrm{RMI}_{\mathrm{RR}}$ composition for risk reduction.

\subsection{Indicators for disaster management}

The goal of disaster management is to provide appropriate response and recovery efforts following a disaster. It is a function of the degree of preparation of the responsible institutions as well as the community as a whole. The goal is to respond efficiently and appropriately when risk has become disaster. Effectiveness implies that the institutions (and other actors) involved have adequate organizational abilities, as well as the capacity and plans in place to address the consequences of disasters. Figure 2 shows the $\mathrm{RMI}_{\mathrm{DM}}$ composition for disaster management.

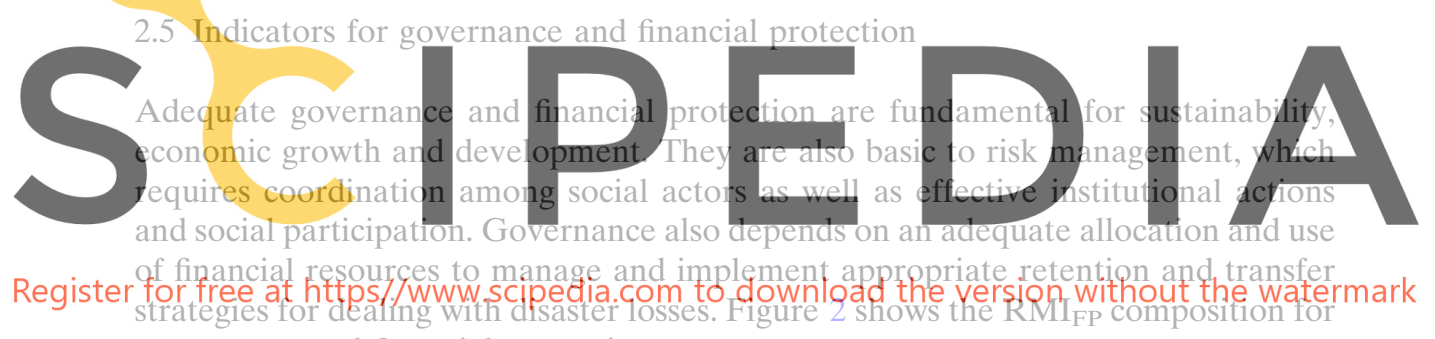

governance and financial protection.

As an example, Table 1 presents the benchmark levels for the indicator RR5 of risk reduction policy. Tables of benchmarks for countries, sub-national regions and cities are not the same but, in general, they are basically similar. Some indicators may change due to scale issues and public responsibilities. The tables of benchmark for all the indicators used in the article can be consulted in http:// www.manizales.unal.edu.co/ and in Cardona et al. (2004, 2005).

Table 1 Benchmarks for indicator RR5

RR5. Updating and enforcement of safety standards and construction codes:

1. Voluntary use of norms and codes from other countries without major adjustments.

2. Adaptation of some requirements and specifications according to some national and local criteria and particularities.

3. Promulgation and updating of obligatory urban norms based on international or national norms that have been adjusted according to the hazard evaluations.

4. Technological updating of the majority of security and construction code norms for new and existing buildings with special requirements for special buildings and life lines.

5. Permanent updating of codes and security norms: establishment of local regulations for construction in the city based on urban microzonation, and their strict control and implementation. 


\section{Examples of application}

In the framework of the Disaster Risk Management Indicators Program in the Americas, Colombia and other ten countries of Latin America and the Caribbean were evaluated (Cardona 2005). In addition, the RMI for Bogota and the 32 departments of Colombia was estimated with the participation of officials in charge of institutions related to risk management in each place. The indicators for each policy were obtained after a broad process of consultations and agreement, with the participation of local evaluators and of well-known international advisors. In this section some cases of study are presented to illustrate the application of RMI at local (urban), national and sub-national level.

\subsection{Urban level: Bogotá, Colombia}

Risk management benchmarking and weights of each indicator were evaluated by officials of the Directorate for Risk Mitigation and Emergency Preparedness (DPAE) of Bogotá, Colombia, and by academics of the city. Tables 2-5 show the qualifications made in different periods between 1985 and 2003 for the indicators shown in Fig. 2. These qualifications are according to the scale given in Sect. 2: (1) low, (2) incipient, (3) significant, (4) outstanding, and (5) optimal.
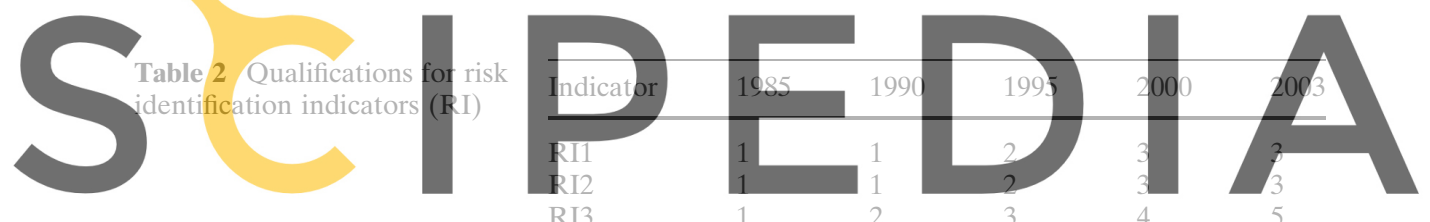

Register for free at https//www.scipe Rifia.com to download the verşion withơ RI6

Table 3 Qualifications for risk reduction indicators (RR)

\begin{tabular}{llllll}
\hline Indicator & 1985 & 1990 & 1995 & 2000 & 2003 \\
\hline RR1 & 1 & 2 & 2 & 3 & 4 \\
RR2 & 1 & 1 & 1 & 1 & 2 \\
RR3 & 1 & 1 & 1 & 3 & 4 \\
RR4 & 1 & 2 & 2 & 3 & 4 \\
RR5 & 2 & 2 & 2 & 4 & 4 \\
RR6 & 1 & 1 & 1 & 2 & 3 \\
\hline
\end{tabular}

Table 4 Qualifications for disaster management (DM)

\begin{tabular}{llllll}
\hline Indicator & 1985 & 1990 & 1995 & 2000 & 2003 \\
\hline DM1 & 1 & 2 & 2 & 3 & 3 \\
DM2 & 1 & 1 & 1 & 2 & 3 \\
DM3 & 1 & 1 & 1 & 2 & 2 \\
DM4 & 1 & 1 & 1 & 1 & 3 \\
DM5 & 1 & 1 & 1 & 2 & 3 \\
DM6 & 1 & 1 & 1 & 1 & 2 \\
\hline
\end{tabular}


Table 5 Qualifications for financial protection (FP)

\begin{tabular}{llllll}
\hline Indicator & 1985 & 1990 & 1995 & 2000 & 2003 \\
\hline FP1 & 1 & 2 & 2 & 3 & 3 \\
FP2 & 1 & 4 & 4 & 4 & 4 \\
FP3 & 1 & 1 & 3 & 3 & 4 \\
FP4 & 1 & 1 & 1 & 1 & 1 \\
FP5 & 1 & 1 & 1 & 2 & 3 \\
FP6 & 1 & 1 & 2 & 2 & 3 \\
\hline
\end{tabular}

The weights were also obtained according to the opinion of the risk management authorities of the city of Bogotá. The AHP, which is explained in Appendix, was applied to estimate these weights. Table 6 shows the results obtained for the weights of each public policy. Although it is also feasible to assign a weight to each composite subindex representing the performance of the city in each of the four policy areas, such weights were assumed to be equal.

Figure 3 shows an example of calculation of an index, in this case the $\mathrm{RMI}_{\mathrm{DM}}$. Figure $3 \mathrm{a}$ shows the membership functions for the qualifications of the disaster management indicators for the year 2003, which is shown in Table 4. Figure 3b shows the union of the fuzzy sets corresponding to the weighted qualifications, that is, their envelope according to Eq. 6. The defuzzification process corre-

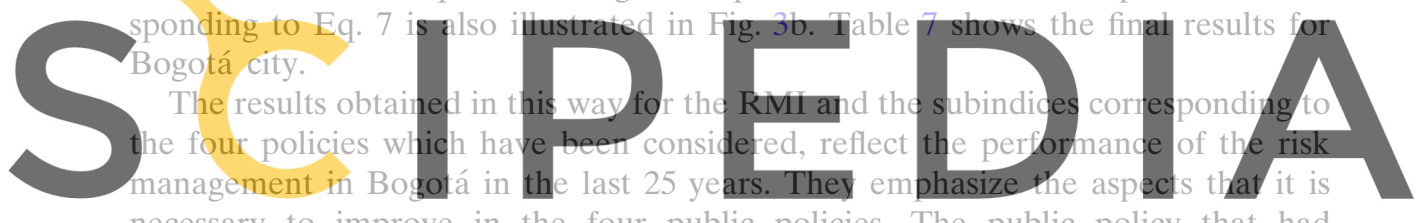
necessary to improve in the four public policies. The public policy that had

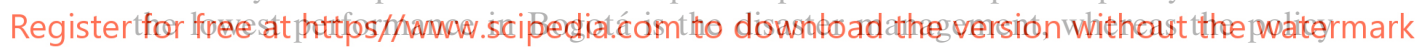
with the greater performance is the risk identification followed by the financial protection.

Considering the localities or urban districts in which is divided the city, a detailed study was also for 2003 performed starting from the qualifications made by DPAE using the same methodology. Figure 4 shows the final results of the RMI by localities. From these results, it is possible to assert that, at urban level, risk management should be performed mainly by the central administration of the city. Localities have not the possibility of developing independently significant tasks because they are too small areas that have not sufficient capacity and autonomy to deal with some specialized activities.

Table 6 Weights for the set of indicators

\begin{tabular}{lllll}
\hline Weight & RI & RR & DM & FP \\
\hline$w_{1}$ & 0.05 & 0.14 & 0.11 & 0.21 \\
$w_{2}$ & 0.22 & 0.09 & 0.11 & 0.46 \\
$w_{3}$ & 0.36 & 0.07 & 0.40 & 0.12 \\
$w_{4}$ & 0.22 & 0.31 & 0.22 & 0.05 \\
$w_{5}$ & 0.05 & 0.20 & 0.05 & 0.12 \\
$w_{6}$ & 0.12 & 0.19 & 0.11 & 0.04 \\
\hline
\end{tabular}


a) Weighted Membership Functions

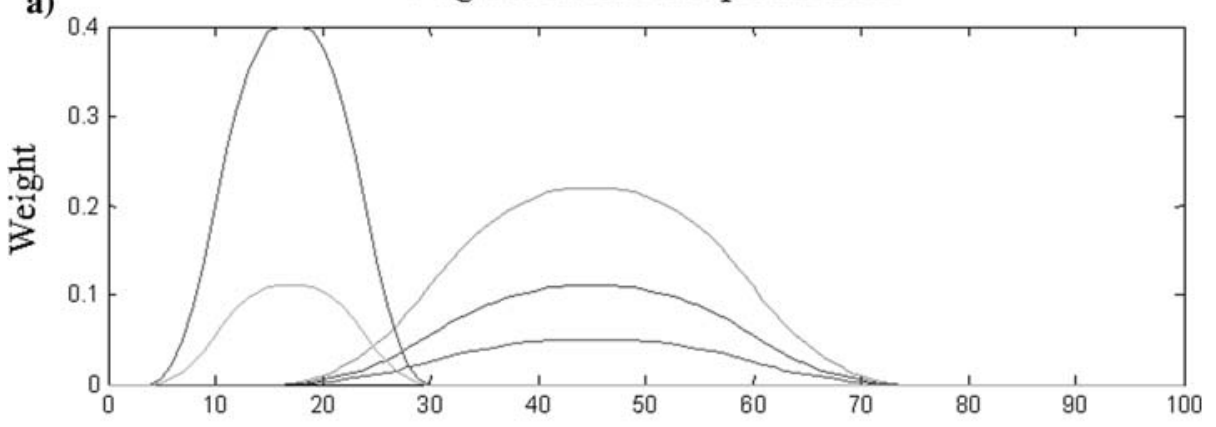

b)

Union and Defuzzification

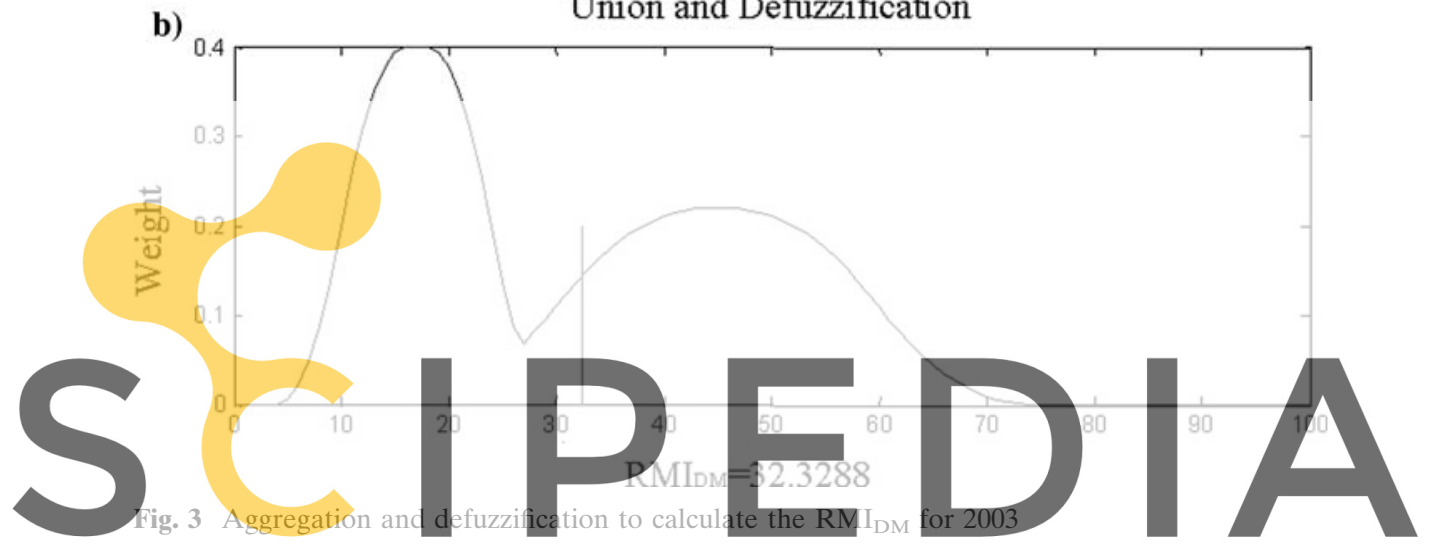

Register for free at https//www.scipedia.com to download the version without the watermark 3.2 National level: Colombia

Risk management benchmarking and weights of each indicator were evaluated by officials of the National Directorate for Disaster Prevention and Emergency Response (DNPAD) and by academics of Centre of Studies on Disasters and Risks (CEDERI) of the University of Los Andes. Tables 8-11 show the qualifications made in different periods between 1985 and 2003, according to the given scale, for the indicators of the four public policies.

Again, the weights were obtained starting from the opinion of the authorities of the DNPAD of Colombia and by applying the AHP. Table 12 displays the final results of the risk management indices obtained for Colombia after the weighted union and the defuzzification of the qualifications for each public policy.

Table 7 Risk management indices for Bogotá

\begin{tabular}{lrrrrr}
\hline Index & 1985 & 1990 & 1995 & 2000 & 2003 \\
\hline RMI $_{\text {RI }}$ & 4.56 & 13.90 & 35.57 & 56.15 & 67.10 \\
RMI $_{\text {RR }}$ & 11.03 & 13.90 & 13.90 & 46.14 & 56.72 \\
RMI $_{\text {DM }}$ & 4.56 & 8.25 & 8.25 & 24.00 & 32.33 \\
RMI $_{\text {FP }}$ & 4.56 & 57.49 & 54.80 & 57.64 & 61.44 \\
RMI & 6.18 & 23.38 & 28.13 & 45.98 & 54.40 \\
\hline
\end{tabular}




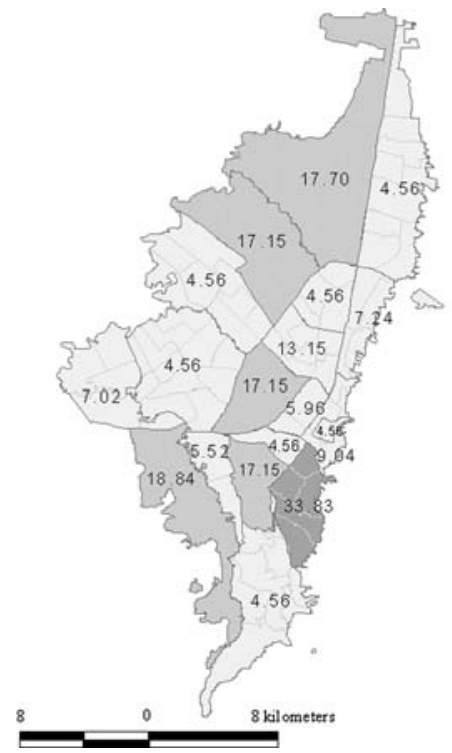

\section{RMI for localities}
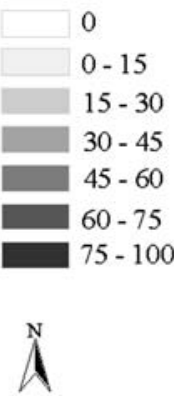

Fig. 4 Values of RMI for the localities of Bogotá, 2003

Table 8 Qualifications for risk identification indicators (RI)

\begin{tabular}{llllll}
\hline Indicator & 1985 & 1990 & 1995 & 2000 & 2003 \\
\hline RI1 & 2 & 3 & 3 & 4 & 4 \\
RI2 & 1 & 2 & 3 & 3 & 3 \\
RI3 & 2 & 2 & 3 & 4 & 4 \\
RI4 & 1 & 1 & 2 & 3 & 3 \\
RI5 & 1 & 1 & 3 & 2 & 2 \\
RI6 & 1 & 2 & 3 & 2 & 2 \\
\hline
\end{tabular}

Table 9 Qualifications for risk reduction indicators $(\mathrm{RR})$

\begin{tabular}{llllll}
\hline Indicator & 1985 & 1990 & 1995 & 2000 & 2003 \\
\hline RR1 & 1 & 2 & 2 & 3 & 3 \\
RR2 & 1 & 2 & 3 & 2 & 2 \\
RR3 & 1 & 1 & 2 & 2 & 2 \\
RR4 & 1 & 2 & 3 & 2 & 2 \\
RR5 & 2 & 2 & 3 & 4 & 4 \\
RR6 & 1 & 1 & 2 & 3 & 3 \\
\hline
\end{tabular}

Table 10 Qualifications for disaster management (DM)

\begin{tabular}{llllll}
\hline Indicator & 1985 & 1990 & 1995 & 2000 & 2003 \\
\hline DM1 & 1 & 2 & 2 & 3 & 3 \\
DM2 & 1 & 1 & 2 & 2 & 2 \\
DM3 & 1 & 2 & 2 & 2 & 2 \\
DM4 & 1 & 1 & 1 & 2 & 2 \\
DM5 & 1 & 1 & 2 & 1 & 1 \\
DM6 & 1 & 1 & 1 & 2 & 2 \\
\hline & & & & &
\end{tabular}


Table 11 Qualifications for financial protection (FP)

\begin{tabular}{llllll}
\hline Indicator & 1985 & 1990 & 1995 & 2000 & 2003 \\
\hline FP1 & 1 & 2 & 3 & 2 & 2 \\
FP2 & 1 & 2 & 3 & 2 & 2 \\
FP3 & 1 & 1 & 2 & 2 & 2 \\
FP4 & 1 & 1 & 2 & 2 & 2 \\
FP5 & 1 & 1 & 2 & 3 & 3 \\
FP6 & 1 & 2 & 2 & 3 & 3 \\
\hline
\end{tabular}

Table 12 Risk management indices for Colombia

\begin{tabular}{lrrrrr}
\hline Index & 1985 & 1990 & 1995 & 2000 & 2003 \\
\hline RMI $_{\text {RI }}$ & 10.54 & 25.07 & 32.46 & 48.41 & 48.41 \\
RMI $_{\text {RR }}$ & 10.97 & 13.96 & 39.28 & 44.46 & 44.46 \\
RMI $_{\text {DM }}$ & 4.56 & 12.49 & 12.49 & 28.73 & 28.73 \\
RMI $_{F P}$ & 4.56 & 12.49 & 31.50 & 39.64 & 39.64 \\
RMI & 7.66 & 16.00 & 28.93 & 40.31 & 40.31 \\
\hline
\end{tabular}

Figures 5 and 6 show that risk identification and risk reduction have been intensive in Colombia during the period of analysis. According to this analysis, at present, the government of Colombia attempts to direct its efforts at formulating, implementing, and to the policy evaluation of risk management, according to these achievements and performance targets (SIRE 2005).

\subsection{Results for Latin America and the Caribbean}

The risk management was evaluated for the following countries of Latin America and the Caribbean region (LAC): Argentina, Chile, Colombia, Costa Rica, Dominican Republic, Ecuador, El Salvador, Guatemala, Jamaica, Mexico and Peru.

Risk management benchmarking and weights of each indicator were made by national advisors and officials of institutions related to disaster risk management of each country (Cardona et al. 2004, 2005). Figures 7-10 illustrate the values of the components of RMI and Fig. 11 shows the final results of the RMI for the countries every 5 years from 1985 to 2000.

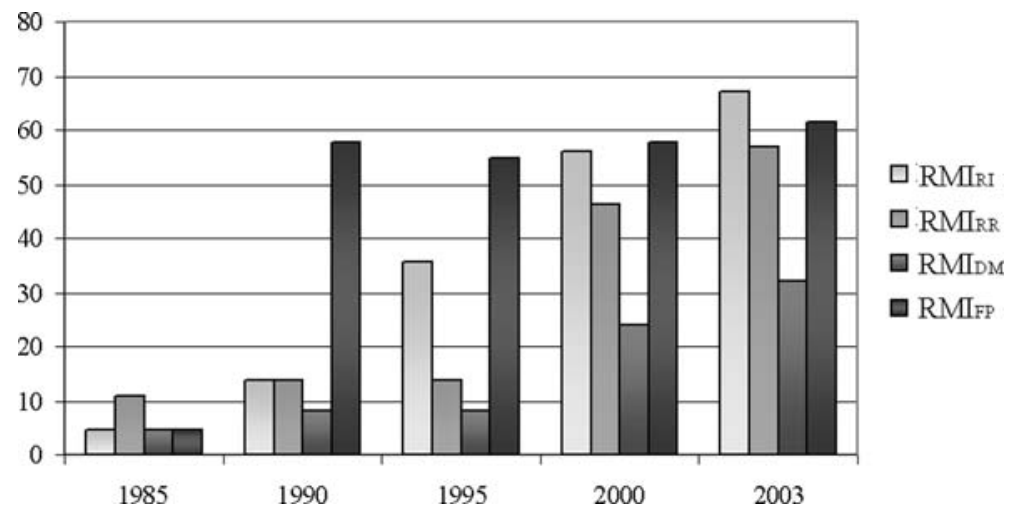

Fig. 5 Risk management indices for each public policy 


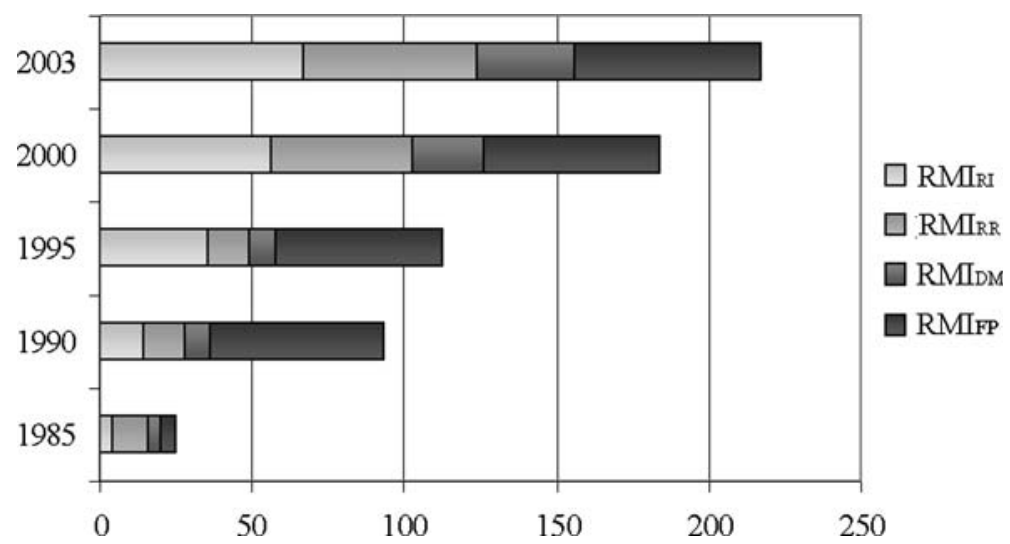

Fig. 6 RMI evolution from 1985 to 2003

\section{RMIRI}

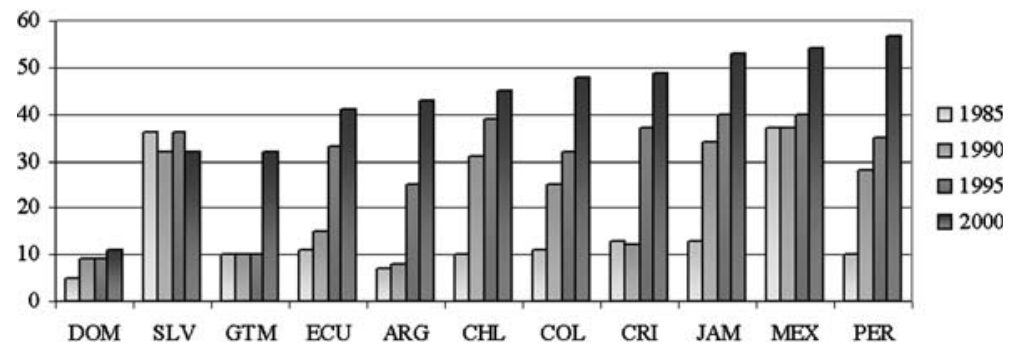

Fig. 7 RMI for risk identification in LAC, 1985-2000

RMIRR

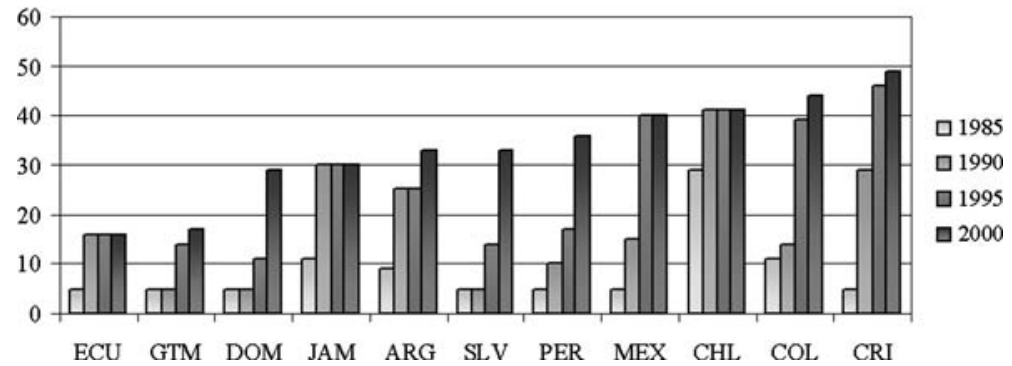

Fig. 8 RMI for risk reduction in LAC, 1985-2000

The analysis shows that Dominican Republic, Ecuador and Argentina have made the least progress over the last few years. El Salvador and Guatemala posted a slightly better performance. Peru and Colombia showed even more improvement, while Chile, Costa Rica, Jamaica and Mexico posted the most significant advances in risk management practice. The overall tendency since the 1980s has been one of increased concern for risk management. As a result, the evaluation of advances 


\section{RMIdм}

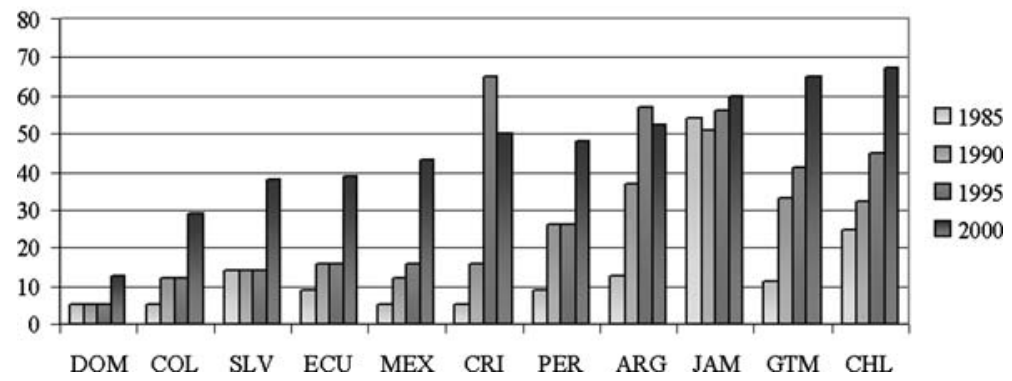

Fig. 9 RMI for disaster management in LAC, 1985-2000

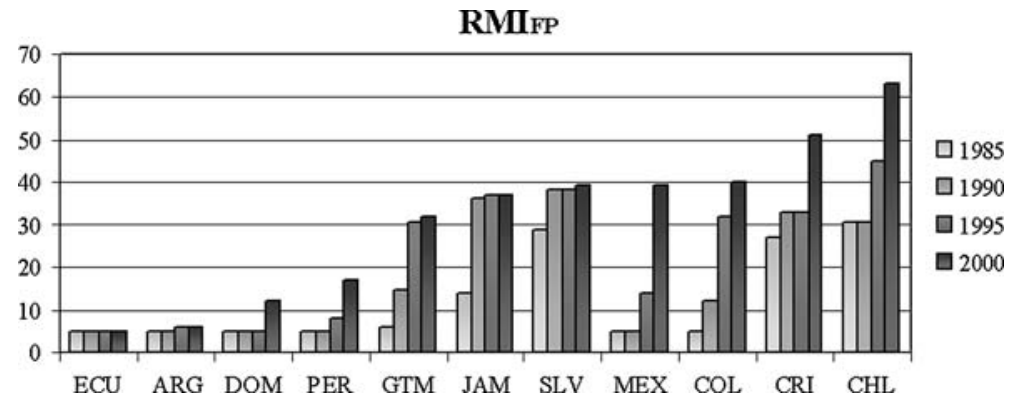

Fig. 10 RMI for financial protection, 1985-2000

RMI

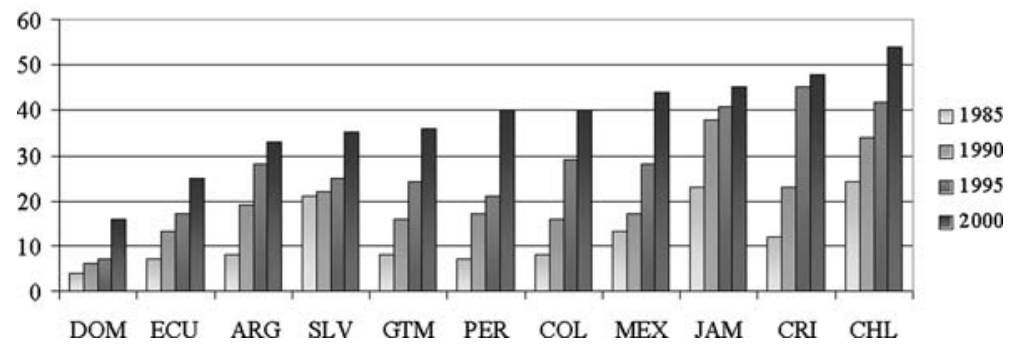

Fig. 11 RMI for the countries, 1985-2000

made has improved from "low" to "significant" in the majority of cases. On average, risk management performance is something better than "incipient" and the feasible effectiveness is still very low (0.2-0.3). This suggests that considerable efforts are required to promote effective and sustainable risk management, even in the more advanced countries. In general, the greatest advances have been made in risk identification and disaster management. Risk reduction, financial protection and institutional organization have as yet been approached very timidly. 


\subsection{Sub-national level: Departments of Colombia}

The methodology was adapted to evaluate risk management performance at subnational level. The RMI was evaluated for the 32 departments of Colombia. Figure 12 shows a RMI map.

Risk management benchmarking of each indicator were evaluated by officials of the DNPAD, Colombia, and by academics of CEDERI. The RMI was evaluated only for 2004. Department of Antioquia and Bogota capital district, posted the most significant advances in risk management practice. Valle del Cauca, Risaralda, Quindio, Nariño, Magdalena, Cundinamarca and Caldas, posted the same level in risk management. The lower values of RMI are shown by the departments of Vichada, Vaupes, Putumayo, Guajira, Guaviare, Guainía, Choco, Cordoba, Cesar and Arauca, which have made the least progress in the four public policies of risk management.

\section{Conclusions}

The RMI is the first systematic and consistent international index developed to measure risk management performance. The conceptual and technical bases of this index are robust, despite the fact that it is inherently subjective. The RMI permits a systematic and quantitative benchmarking of each country during different periods, as well as comparisons across countries. This index not only enables the depiction of disaster risk management at the national level, but also at the sub-national and urban level, allowing the creation of risk management performance benchmarks in order to establish performance targets for improving management effectiveness.

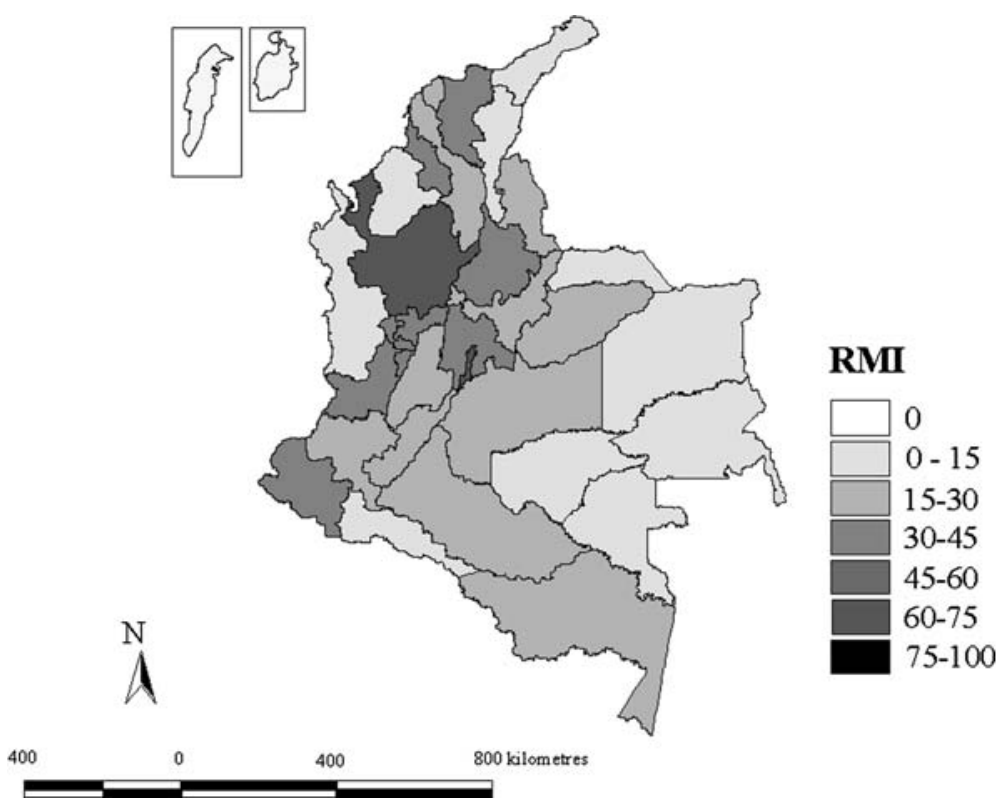

Fig. 12 RMI for the departments of Colombia at 2004 
The RMI is novel and far more wide reaching in its scope than other similar attempts in the past. It is certainly the one that can show the fastest rate of change given improvements in political will or deterioration of governance. The RMI can show acute annual or biennial improvements due to political decisions and implementations of measures of risks management. That is important from the point of view of giving positive reinforcement to national or sub-national governments, as well as of providing for improved social protection, while slower, gradual socioeconomic progress is being made. It is the reason why the RMI is a useful tool for organizations like the Inter-American Development Bank (IDB), which financed this study.

This index has the advantage of being composed of measures that directly map sets of specific decisions/actions onto sets of desirable outcomes. Although the method may be refined or simplified in the future, its approach is quite innovative because it allows the measurement of risk management and its feasible effectiveness. The new IDB Action Plan for disaster reduction in the Latin America and the Caribbean and the new country's strategy papers for development assistance made by decision-makers of the bank and of the countries, have been based on the outcomes and analyses of these evaluations.

Acknowledgements The Risk Management Index, RMI herein described, was developed to evaluate risk management performance and effectiveness of countries of Latin America and the Caribbean in the framework of the Disaster Risk Management Indicators Program in Americas (ATN/JF-7907-RG Operation), led by the Institute of Environmental Studies, IDEA, of the National University of Colombia, in Manizales, for the Inter-American Development Bank, IDB. In addition, it was applied to the departments of Colombia and Bogota to illustrate its application at sub-national and local level. Program reports, technical details and the application results for the countries in Americas can be consulted in the following web page: http://www.manizales.unal.edu.co/

\section{Appendix}

AHP is a technique widely used for multi-attribute decision making (Saaty 1980, 1987; Saaty and Vargas 1991). It enables decomposition of a problem into hierarchy and assures that both qualitative and quantitative aspects of a problem are incorporated in the evaluation process, during which opinion is systematically extracted by means of pairwise comparisons. AHP allows the application of data, experience, knowledge, and intuition of a logical and deep form.

The core of AHP is an ordinal pairwise comparison of attributes, indicators in this context, in which preference statements are addressed. For a given objective, the comparisons are made per pairs of indicators by first posing the question "Which of the two is the more important?" and second "By how much?" The strength of preference is expressed on a semantic scale of 1-9, which keeps measurement within the same order of magnitude. A preference of 1 indicates equality between two indicators while a preference of 9 indicates that one indicator is 9 times larger or more important than the one to which it is being compared. The relative weights of the indicators are calculated using an eigenvector technique. One of the advantages of this method is that it is able to check the consistency of the comparison matrix through the calculation of the eigenvalues. 
The matrices allowing the comparison of the assigned relative importance, together with the respective index of consistency and the weights or priority vector, have been obtained for the indicators of each policy for the example of Bogotá (see Tables 13-20).

Table 13 Matrix of comparisons for risk identification

\begin{tabular}{lllllll}
\hline & RI1 & RI2 & RI3 & RI4 & RI5 & RI6 \\
\hline RI1 & 1 & 0.2 & 0.2 & 0.2 & 1 & 0.33 \\
RI2 & 5 & 1 & 0.5 & 1 & 5 & 2 \\
RI3 & 5 & 2 & 1 & 2 & 5 & 4 \\
RI4 & 5 & 1 & 0.5 & 1 & 5 & 2 \\
RI5 & 1 & 0.2 & 0.2 & 0.2 & 1 & 0.33 \\
RI6 & 3 & 0.5 & 0.25 & 0.5 & 3 & 1 \\
\hline
\end{tabular}

Eigenvalue $=6.0877 ; \mathrm{CI}=0.018 ; \mathrm{CR}=0.014$

Table 14 Importance for risk identification

\begin{tabular}{lll}
\hline Indicator & $\begin{array}{l}\text { Principal } \\
\text { eigenvector }\end{array}$ & Priority vector \\
\hline RI1 & 0.0982 & 0.05 \\
RI2 & 0.4441 & 0.22 \\
RI3 & 0.7280 & 0.36 \\
RI4 & 0.4441 & 0.22 \\
RI5 & 0.0969 & 0.05 \\
RI6 & 0.2381 & 0.12 \\
\hline
\end{tabular}

Table 15 Matrix of comparisons for risk reduction

\begin{tabular}{lllllll}
\hline & RR1 & RR2 & RR3 & RR4 & RR5 & RR6 \\
\hline RR1 & 1 & 1 & 0.25 & 0.5 & 3 & 1 \\
RR2 & 1 & 1 & 0.25 & 0.50 & 3 & 1 \\
RR3 & 4 & 4 & 1 & 2 & 5 & 4 \\
RR4 & 2 & 2 & 0.5 & 1 & 5 & 2 \\
RR5 & 0.33 & 0.33 & 0.2 & 0.2 & 1 & 0.33 \\
RR6 & 1 & 1 & 0.25 & 0.5 & 3.0 & 1 \\
\hline
\end{tabular}

Eigenvalue $=6.1343 ; \mathrm{CI}=0.027 ; \mathrm{CR}=0.022$

Table 16 Importance for risk reduction

\begin{tabular}{lll}
\hline Indicator & $\begin{array}{l}\text { Principal } \\
\text { eigenvector }\end{array}$ & Priority vector \\
\hline RR1 & 0.3172 & 0.14 \\
RR2 & 0.1896 & 0.09 \\
RR3 & 0.1597 & 0.07 \\
RR4 & 0.6900 & 0.31 \\
RR5 & 0.4382 & 0.20 \\
RR6 & 0.4122 & 0.19 \\
\hline
\end{tabular}


Table 17 Matrix comparisons for disaster management

\begin{tabular}{lllllll}
\hline & DM1 & DM2 & DM3 & DM4 & DM5 & DM6 \\
\hline DM1 & 1 & 2 & 2 & 5 & 4 & 5 \\
DM2 & 0.5 & 1 & 1 & 5 & 2 & 5 \\
DM3 & 0.5 & 1 & 1 & 5 & 2 & 5 \\
DM4 & 0.2 & 0.2 & 0.2 & 1 & 1 & 1 \\
DM5 & 0.25 & 0.5 & 0.5 & 3 & 0.33 & 3 \\
DM6 & 0.2 & 0.2 & 0.2 & 1 & 1 \\
\hline
\end{tabular}

Eigenvalue $=6.0684 ; \mathrm{CI}=0,014 ; \mathrm{CR}=0.011$

Table 18 Importance for disaster management

\begin{tabular}{lll}
\hline Indicator & $\begin{array}{l}\text { Principal } \\
\text { eigenvector }\end{array}$ & Priority vector \\
\hline DM1 & 0.2272 & 0.11 \\
DM2 & 0.2272 & 0.11 \\
DM3 & 0.8023 & 0.40 \\
DM4 & 0.4392 & 0.22 \\
DM5 & 0.0923 & 0.05 \\
DM6 & 0.2272 & 0.11 \\
\hline
\end{tabular}

Table 19 Matrix of comparisons for financial protection

\begin{tabular}{lllllll}
\hline & PF1 & PF2 & PF3 & PF4 & PF5 & PF6 \\
\hline FP1 & 1 & 0.33 & 2 & 5 & 2 & 5 \\
FP2 & 3 & 1 & 5 & 6 & 3 & 1 \\
FP3 & 0.5 & 0.2 & 1 & 1 & 0.33 & 3 \\
FP4 & 0.2 & 0.167 & 0.33 & 3 & 1 & 1 \\
FP5 & 0.5 & 0.2 & 1 & 1 & 0.33 & 3 \\
FP6 & 0.2 & 0.167 & 0.167 & & 1 \\
\hline
\end{tabular}

Eigenvalue $=6.0909 ; \mathrm{CI}=0.018 ; \mathrm{CR}=0.015$

Table 20 Importance for financial protection

\begin{tabular}{lll}
\hline Indicator & $\begin{array}{l}\text { Principal } \\
\text { eigenvector }\end{array}$ & Priority vector \\
\hline FP1 & -0.3942 & 0.21 \\
FP2 & -0.8583 & 0.46 \\
FP3 & -0.2159 & 0.12 \\
FP4 & -0.0887 & 0.05 \\
FP5 & -0.2159 & 0.12 \\
FP6 & -0.0828 & 0.04 \\
\hline
\end{tabular}

\section{References}

Bates FL, Peacock WG (1992) Measuring disaster impact on household living conditions: the domestic assets approach. Int J Mass Emerg Disasters 10(1):133-160

Benson C (2003) Potential approaches to the development of indicators for measuring risk from a macroeconomic perspective. IDB/IDEA Program on Indicators for Disaster Risk Management, Universidad Nacional de Colombia, Manizales, http://www.manizales.unal.edu.co/ 
Briguglio L (2003a) Some considerations with regard to the construction of an index of disaster risk with special reference to islands and small states. IDB/IDEA Program on Indicators for Disaster Risk Management, Universidad Nacional de Colombia, Manizales, http://www.manizales.unal.edu.co/

Briguglio L (2003b) Methodological and practical considerations for constructing socio-economic indicators to evaluate disaster risk. IDB/IDEA Program on Indicators for Disaster Risk Management, Universidad Nacional de Colombia, Manizales, http://www.manizales.unal.edu.co/

Cardona OD (2001) Estimación Holística del Riesgo Sísmico utilizando Sistemas Dinámicos Complejos. Doctoral Thesis, Technical University of Catalonia, Barcelona

Cardona OD (2005) Indicators of disaster risk and risk management. Summary report. IDB/IDEA Program on Indicators for Disaster Risk Management. Inter-American Development Bank, Sustainable Development Department Environment Division, Washington DC

Cardona OD, Hurtado JE, Duque G, Moreno A, Chardon AC, Velásquez LS, Prieto SD (2003a) The notion of disaster risk. Conceptual framework for integrated risk management. IDB/IDEA Program on Indicators for Disaster Risk Management, Universidad Nacional de Colombia, Manizales, http://www.manizales.unal.edu.co/

Cardona OD, Hurtado JE, Duque G, Moreno A, Chardon AC, Velásquez LS, Prieto SD (2003b) Indicators for risk measurement: fundamentals for a methodological approach. IDB/IDEA Program on Indicators for Disaster Risk Management, Universidad Nacional de Colombia, Manizales, http://www.manizales.unal.edu.co/

Cardona OD, Hurtado JE, Duque G, Moreno A, Chardon AC, Velásquez LS, Prieto SD (2004) Disaster risk and risk management benchmarking: a methodology based on indicators at national level. IDB/IDEA Program on Indicators for Disaster Risk Management, Universidad Nacional de Colombia, Manizales, http://www.manizales.unal.edu.co/

Cardona OD, Hurtado JE, Duque G, Moreno A, Chardon AC, Velásquez LS, Prieto SD (2005) System of indicators for disaster risk management: program for Latin America and the Caribbean: main technical report. IDB/IDEA Program on Indicators for Disaster Risk Management, Universidad Nacional de Colombia, Manizales, http://www.manizales.unal.edu.co/

Carreño ML (2001) Sistema Experto para la Evaluación del Daño Postsísmico en Edificios. Master thesis, Department of Civil Engineering and Environment, University of Los Andes, Bogota, Colombia

Carreño ML, Cardona OD, Barbat AH (2004) Metodología para la evaluación del desempeño de la gestión del riesgo. CIMNE monograph IS-51, Technical University of Catalonia, Barcelona, Spain

Carreño ML, Cardona OD, Barbat AH (2005) Sistema de indicadores para la evaluación de riesgos. CIMNE monograph, Technical University of Catalonia, Barcelona, Spain

Carreño ML, Cardona OD, Barbat AH (2007) Urban seismic risk evaluation: a holistic approach. Nat Hazards 40:137-172

Comfort LK (1999) Shared risk: complex systems in seismic response. Pergamon, New York

Cutter SL (ed) (1994) Environmental risks and hazards. Prentice Hall, New Jersey

Davidson R (1997) An urban earthquake disaster risk index. The John A. Blume Earthquake Engineering Center, Department of Civil Engineering, Stanford University, Report No. 121, Stanford

Davis I (2003) The effectiveness of current tools for the identification, measurement, analysis and synthesis of vulnerability and disaster risk. IDB/IDEA Program on Indicators for Disaster Risk Management, Universidad Nacional de Colombia, Manizales, http://www.manizales.unal.edu.co/

ISDR (2003) A framework to guide and monitor disaster risk reduction, http://www.unisdr.org/ dialogue/basicdocument.htm draft proposal, ISDR/UNDP

Masure P (2003) Variables and indicators of vulnerability and disaster risk for landuse and urban or territorial planning. IDB/IDEA Program on Indicators for Disaster Risk Management, Universidad Nacional de Colombia, Manizales, http://www.manizales.unal.edu.co/

Mitchell T (2003) An operational framework for mainstreaming disaster risk reduction. Benfield Hazard Research Centre Disaster Studies Working Paper 8, London

Munda G (2003) Methodological exploration for the formulation of a socio-economic indicators model to evaluate disaster risk management at the national and sub-national levels. A social multi-criterion model. IDB/IDEA Program on Indicators for Disaster Risk Management, Universidad Nacional de Colombia, Manizales, http://www.manizales.unal.edu.co/

Puente S (1999) Social vulnerability to disasters in Mexico City: an assessment method. In: Mitchell JK (ed) Crucibles of hazard: mega-cities and disasters in transition. United Nations University Press, New York 
Saaty TL (1980) The analytic hierarchy process. McGraw-Hill Book Co., NY

Saaty TL (1987) The analytic hierarchy process-what it is and how it is used. Math Model 9:161-176

Saaty TL, Vargas LG (1991) Prediction, projection, and forecasting: applications of the analytical hierarchy process in economics, finance, politics, games, and sports. Kluwer Academic Publishers, Boston

SIRE (2005) http://www.sire.gov.co, Bogotá, Colombia

Tucker BE, Erdik MÖ, Hwang CN (eds) (1994) Issues in urban earthquake risk. Springer, Dordrecht, The Netherlands

UNDP (2004) Reducing disaster risk: a challenge for development. A Global Report, United Nations Development Program, Disaster Risk Index DRI, Geneva

World Bank (2004) Identification of global natural disaster risk hotspots. Center for Hazard and Risk Research at University of Columbia, Washington 